\title{
Social Life after Covid-19: a Linguistic Study in light of Shannon-Weaver's Model of Communication
}

\author{
Fatma Tawakl Gaber* \\ fatma.english88@gmail.com
}

\begin{abstract}
A lot of people around the world yearn for the day when their lives will return to the better after nearly a year has passed since the emergence of the new Corona virus (Covid-19). This epidemic has radically changed the way people live and their social interaction. It has had a global impact; life has changed a lot after its spread, especially the scientific life where many researchers, scientists and doctors have done many researches for discussing its causes and results. Covid 19 has infected tens of millions of people in the world, killing over 1.5 million people. In addition, prevention measures have paralyzed economy and confused education, entertainment and the rest of the activities that people are familiar with. After the spread of this pandemic, scientific studies and field studies have been increased in various fields to discuss how this virus affected various fields of life such as literature, arts, philosophy, sciences, and social studies. What many scientists expect in 2024 is a return to the lifestyle that all people long for. In this research, the researcher will discuss some aspects of life after the spread of Covid 19 and will shed light on health, social sciences, and field studies through the application of Shannon and Weaver's communication theory which provides a schematic representation of the relationship between the sender, the message, medium of communication, and the recipient to two speeches given by prominent officials and one article written by a unique researcher for portraying life after the pandemic. The chosen theory provides a framework for analyzing how messages are sent and received. It is famous for its ability to explain how messages are mixed and misinterpreted in the process between sending and receiving the message.Thus, the chosen theory will be the main tool for the researcher to communicate speakers' and writers' messages to the whole world.
\end{abstract}

Keywords: Covid 19, Health, Social Sciences, Field Studies, ShanonWeaver model of Communication.

${ }^{*}$ Lecturer -English department -Faculty of Arts- Tanta University

(Social Life after Covid-19...)Dr. Fatma Tawakl Gaber 


\section{Introduction}

\subsection{Theory of Communication}

"Communication is the process that occurs when ideas, information, and feelings are conveyed between groups of individuals for deliberate purposes" (Baguley, 1994, p. 512). It is the exchange of ideas between two or more persons, or a process of transmitting and receiving verbal or non-verbal messages that produce a response (Murphy \& Hildebrandt, 1991). The factors which influence the process of communication are the individual's perception of the environment, the cultural context of the interaction, stress, experience or knowledge, individual characteristics, and technology. Due to the importance of communication, different types of models have been introduced. The most famous models of communication have been presented by Shannon and Weaver, Jakobson, Schramm, and Berlo. Modes of communication are both verbal and nonverbal. Verbal communication encompasses any form of communication involving words, spoken, written or signed. We use verbal communication to inform others of our needs or to impart knowledge. Clarification is a key component of verbal communication. Non-verbal communication includes messages sent through body language such as posture, gestures, eye contact, space, gaze, touch, facial expressions, and physical appearance. The sound of our voice, including pitch, tone, and volume are also forms of non-verbal communication (Lucas, 2015).

Communication process is a great way to learn how to communicate effectively. When performed correctly, the method may typically ensure that the receiver understands the sender's message. It consists of four main components: encoding, medium of transmission, decoding, and feedback. It begins with the sender and ends with the receiver. The sender should have experiences, attitudes, knowledge, skill, perceptions, and culture. All these 
factors influence the message. "The written words, spoken words, and nonverbal language selected are paramount in ensuring the receiver interprets the message as intended by the sender" (Burnett \& Dollar, 1989, p.1). The first step is called the encoding process. The sender must begin translating information into a message in the form of symbols (languages, words, or gestures) that represent concepts. These symbols are used to encode ideas into messages that other participants can understand. This process translates the concepts into the coded message that will be communicated. When encoding a message, the sender has to begin by transmitting what is important to the receiver. The sender needs a channel or a medium of communication.

The channel is the means used to convey the message. Most channels are either oral or written. Common channels include the telephone and a variety of written forms such as letters, and reports. Depending on the parameters of the message, the efficiency of various channels varies. For example, when immediate feedback is necessary, oral communication channels are more effective. In a situation where the message must be delivered to more than a small group of people, written channels are often more effective. The sender should keep in mind that selecting the appropriate channel affects the receiver's understanding. The recipient is the person or people to whom the message is addressed. Feedback is the final link in the communication process. The receiver responds to a message in some way and indicates that reaction to the sender. A verbal remark, a long sigh, a written message, a grin, or some other action could be used as the signal. "Even a lack of response, is in a sense, a form of response" (Bovee\&Thill, 1992, p.3). The sender cannot validate that the receiver has correctly interpreted the message without feedback. Feedback is an important part of the communication process since it allows the sender to assess the 
message's efficacy. In the end, feedback allows the sender to take corrective action in order to clarify a misunderstood message. "Feedback plays an important role by indicating significant communication barriers: differences in background, different interpretations of words, and differing emotional reactions" (Bovee\&Thill, 1992, p.3).

\subsection{Shannon-Weaver's Model of Communication}

One of the earliest models of communication introduced in 1948 was Claude Shannon and Weaver's model. It has been developed by Sabah Al-Fedaghi in 2012 in a research paper entitled "A Conceptual Foundation for the Shannon-Weaver Model of Communication." "It has greatly helped and enhanced the communication process in various fields ("Communication Models," n.d., para.10). Hitesh Bhasin also has handled the main components and parts of an effective communication process which have been put earlier by Shannon and Weaver in an article published in February7, 2021 entitled "Communication Process Definition, Importance, Components and How to Improve." The diagram in figure (1) illustrates how communication takes place. In this model, the information source refers to a person who sends a message with the use of a transmitter. This transmitter can be any instrument today, from phones to computers. The signals that are sent and received can vary, depending on the method of communication. The box at the bottom called NOISE refers to any signals that may interfere with the message being carried such as horn sounds, thunder, and crowd noise. The receiver is the person that receives the message. The model deals with external noises only which affect the messages or signals from external sources (Shannon and Weaver, n.d., para.3). 


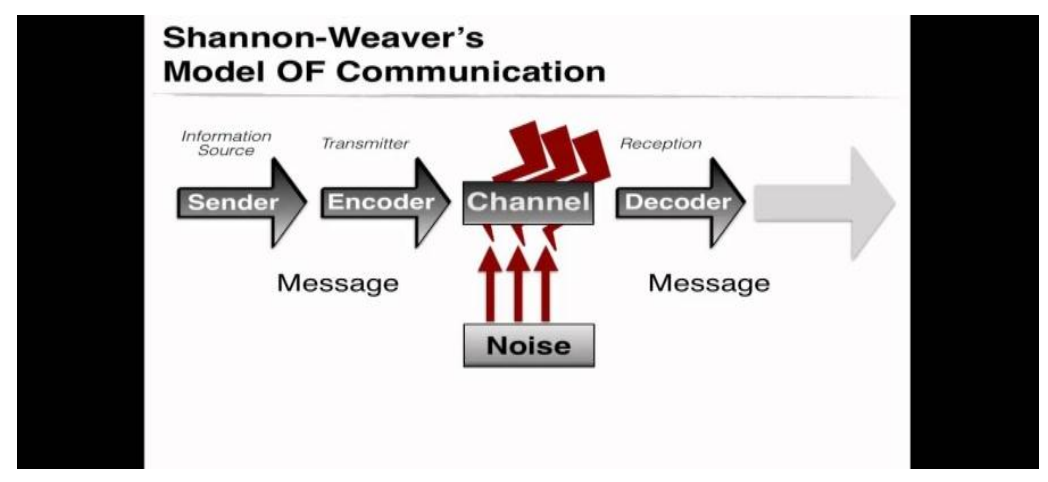

Fig. 1 Schematic diagram of the Shannon-Weaver model

\subsection{Social Life in light of Covid-19}

Nearly a year after the spread of the new Corona virus, life has changed a lot as many doctors have tried hard to find medicines that prevent and limit the spread of this global epidemic. Indeed, a vaccine has been discovered for reducing the spread of this fatal disease and overcome its deadly effects. Many researchers have done several researches to present a clear image of life in light of this epidemic. Many officials have given many speeches and famous researchers wrote various articles to reflect life under the pandemic, shedding light on citizens' health awareness and their commitment to precautionary measures. In addition, many researches, articles and speeches reflected technology, social sciences, and scientific development in the era of the pandemic. Several field studies have been conducted to study this disease more effectively and study its seriousness. Officials on behalf of the World Health Organization spoke about the health status of citizens in the entire Arab world in light of the disease, and they emphasized the necessity of taking the vaccine to put an end to Covid-19.

There are many repercussions and psychological effects of the period of quarantine and social isolation during Corona virus period. The deprivation that everyone experiences has many 
psychological effects as the idea of not practicing customs related to occasions, refraining from visiting parents, practicing religious rituals as usual, and standing in a confrontation with the unknown are all factors that cause a state of anxiety. Based on this, and with the return to normal life and social life, each individual has to fight the factors that cause him negative feelings such as fear, anxiety and tension. If the conditions accompanying the disease are difficult, it is natural for the psychological effects and anxiety to increase even after the end of Covid-19 period. Some people also resorted to virtual communication in the previous stage as an alternative to social communication and social life. However, it cannot replace actual communication. It is necessary for everyone to return to actual communication. Because of the Covid-19 pandemic, many of us are remaining at home and engaging in less social interactions and physical activities. This can be harmful to both your physical and mental health (WHO, 2021).

Symptoms of Covid-19 might last for months. This virus can cause long-term health problems by causing damage to the lungs, heart, and brain. The majority of persons with Coronavirus disease recover completely within a few weeks. However, some people, even those with mild forms of the condition, continue to have symptoms after they have recovered. These persons are known as "long haulers," and their conditions are referred to as "post-Covid-19 syndrome" or "long Covid-19." Post-Covid-19 conditions are a term used to describe these health issues. They're thought to be Covid-19 side effects that last longer than four weeks after one has been diagnosed with the virus. Much remains unknown regarding the long-term effects of Covid-19, but research is ongoing. Doctors should regularly monitor persons who have had this pandemic for evaluating how their organs are functioning after their recovery, according to the researchers. After recovering from Covid-19, many prominent medical centers 
are opening many clinics to treat people who have persistent symptoms or illnesses. Most Covid-19 patients recover rapidly. However, because of the long-term consequences of Covid-19, it is even more critical to prevent Covid-19 from spreading by taking safeguards. Wearing masks, social distancing, avoiding crowds, getting a vaccine when available, and keeping hands clean are all precautions to take (Mayo, 2021).

After about one year from the spread of the Corona Virus (Covid-19) pandemic, different governments have concentrated heavily on scientific research in making their decisions. However, much work is still needed to bridge the influential social science gap, especially because the world's policy makers will face the challenges and prospects of recovery from the virus even after the pandemic, and that every political choice will contribute to shaping the features of our post-pandemic world. The pandemic and applied research in the field of social sciences can provide proofs that can be used in decision-making processes. All of this reflects the scale of the enormous societal challenges we face as a global community, and no single governmental or nongovernmental institution can tackle all of these challenges alone. Generally, Covid-19 pandemic in different social sciences is proved to be a growing threat, leading to exacerbating inequality in employment, health, race, generation, gender, education, geography and digital services. Evidence is still needed to highlight the enormous impact.

A better social science community means finding better capabilities in all areas to contribute to finding relevant solutions to societal problems and to improve responses to potential future crises. The pandemic has provided great impetus to work together and collaborate on a common agenda, but this partnership model is not necessarily the best practice dedicated to addressing public emergencies, but it should become a new standard for post- 
pandemic public policy development. All academics continually strive to show the impact of their research on societies, and they believe that the study of familial life is an example of the impact they can achieve through applied researches in social sciences if they collaborate, identify opportunities to learn from each other, and break down institutional walls and barriers (Ben Break, 2021).

Researches in the field of Social Sciences began to be interested in studying the repercussions of this fatal pandemic. The topic has captured the attention of researchers in their various specializations, and it seems that each research group has its own interests: politicians, economics, management, psychology, and certainly sociology. This is the case of researchers in the West as well as some in Asia and Africa. As for us, it seems that the topic did not receive the attention of our researchers except in the narrowest limits, and did not go beyond the scope of the medical view of the epidemic, its spread, and taking precautions against it. Most researchers in social sciences neither exerted a serious scientific effort in interpreting and monitoring the repercussions of the epidemic nor predicting its results in the opposite of what their peers do in many countries. Most Egyptian researchers do not seem to be contributors to thinking about the pandemic even though it presents an exceptional cosmic occasion in which the entire world is concerned. It does not include a country or even a continent without another. The world's interaction with the efforts in confronting this epidemic also provides fertile material for researchers in social sciences to set a new research agenda, each in their field of specialization (Fawzy, 2021).

In sociology, we need field and case studies related to the change in values as a result of the spread of the virus. How did social institutions interact with the epidemic? Is social awareness at the required level? What is the behavior of the family while 
staying at home? Is there a change in lifestyle and interests, especially since there is more reliance on the internet for communication? In the field of psychology, what are the changes that occurred in the Egyptian personality? What are the feelings, behaviors and attitudes of people in responding to the epidemic that has not visited societies before? These are just questions that need the efforts of researchers to answer for enriching social sciences. Scientific circles in developed countries are preoccupied with these questions, but we are still far from them. Our studies are dominated by the usual questions, and they also produce usual results. It may not be new to assert that this type of studies suffers from a knowledge gap not only in Egypt, but in the entire Arab region. Unfortunately, our researchers, with the exception of a few of them, are waiting for the research production in Western circles for translating what others produce. This is an extended dilemma, and it seems that the horizon to get out of it is not wide. For brilliant researchers, the pandemic presents a new opportunity and constitutes a fertile material for renewing academic research and getting out of the usual molds that are devoid of innovation (Fawzy, 2021).

\section{Objectives of the Study}

This research has both academic and practical benefits:

\subsection{Academic Benefits}

It sheds new light on the significance of communication models and how they can easily assist us in identifying and comprehending the components and relationships that make up the communication process. The researcher attempts to explain how the chosen model represents fresh thoughts on many areas of communication, how it aids in the planning of efficient communication systems, and how it gives inputs for establishing a standard communication system and ensuring effective communication. In addition, the researcher seeks to provide 
communication models as visual representations of communication process. The study proves how communication models are authentic outcomes of systematic study of numerous aspects of communication. A communication model provides a comprehensive understanding of a system or structure, allowing others to comprehend similar systems or structures. It is employed in the realm of communication for research and investigation. The chosen model is referred to as the transmission model of communication. This model is exploited in a manageable way to transfer information. One of the major benefits of this model is that it involves signal transmission of information. This indicates that this model can be used in oral and written forms of communication. In addition, the researcher demonstrates the use of the communication model in assessing real-world problems and preventing future ones. Through this research, she discusses some of the benefits of this model such as how the concept of noise aids in efficient communication by removing noise or problem-causing noise, and how this model views communication as a two-way process, being applicable in general communication. Bhasin (2021) states:

Communication is essential for coordination for people to understand thoughts and ideas of one another. It is essential in decision making. In the absence of proper communication, no proper and efficient decision making is possible. It helps in increasing the managerial efficiency in organizations. It promotes and increases the overall organizational peace and cooperation among all employees holding different places in the hierarchy.

\subsection{Practical Benefit}

This research deals with the fatal effects of the Corona pandemic, focusing on health, social sciences and field studies. It 
reflects the future of social science research in the post-Corona world. After the outbreak of the epidemic, various governments have relied on scientific research in making their decisions. Governments have stressed that more work is still needed to bridge the influential gap of social sciences, especially since policy makers in the world will face the challenges and prospects of recovery from the virus even after the pandemic, and that every political choice that will be made will contribute to shaping our world in the post-pandemic stage. It is possible that applied research in the field of social sciences provides clues and visions that can be used in decision-making processes. This research reflects the societal challenges that we face as a global community, indicating that no party alone can face all these challenges. The researcher addresses the growing threat of the virus and how it exacerbates inequality in employment, health, education and digital services. Social science community works in light of the crisis to find solutions related to societal problems and improve responses to face potential crises in the future. So, the research is also important to evaluate both the social and economic influence of the virus; it studies the psychological impact of the virus on patients. The study reflects the ability of the scientific research in analyzing, predicting, and extracting important information.

\section{Problems of the Study}

The chosen communication model which will be used to analyze the chosen data has been criticized for being based on the hardware aspect which was built for engineering difficulties rather than for promoting communication between human beings. This model does not mention barriers to communication; there is no room for noise. For more critics, the model misrepresents the nature of human communication because human communication is not mathematical in nature. When it comes to human 
communication, this model encounters some difficulty. It was created as a model for telecommunication rather than interpersonal human communication. Another criticism is that the element of feedback was not taken into account. The element of feedback is vital for the completion of communication procedures. The researcher will try to show its effective employment in the analysis of certain speeches and articles given on life after Covid-19, trying to avoid the disadvantages of this model. In applying the chosen model to the chosen data, the researcher will face another problem which is the difficulty in finding suitable speeches on life in light of Covid-19. Some speeches do not tackle life after Covid-19 in detail; some concentrates on health, others on social sciences, and few on field studies. The three issues are more obvious in articles than in speeches given by officials, so the researcher chose to apply the chosen model of communication to both speeches and articles although it is better for this model to be applied to spoken language, not written language. The researcher will try to prove that this model is not only mathematical by applying it to human communication.

\section{Review of Literature}

This research is not the first which tackles life as portrayed after Covid-19. There are some researchers who conducted this study in different needs of the purpose. For the theoretical part, Shannon- Weaver's model of communication has been employed in different other researches for different purposes. For example, in January 2012 Sabah Al-Fedaghi wrote a research paper entitled "A Conceptual Foundation for the Shannon-Weaver Model of Communication." It is regarded as a contribution to the creation of a communication model built on a foundation that is suitable for a wide range of information handling context. To augment current understanding of some of the key concepts used in Shannon- 
Weaver-based models, a new conceptual representation is applied. He attempted to bridge the gap between various communication paradigms and propose a unified approach.The results seem very promising as a step toward developing a unified approach to the study of communication (Al-Fedaghi, 2012). In January 2013, Dirk Baecker in a research paper entitled "Systemic Theories of Communication" explained:

In order to overcome the engineering model of signaling (rather than communication) offered by Shannon and Weaver systemic theories drop the assumption of a given set of possible messages any one message is considered to be selected from, and instead assume that the set of possible messages is to be constructed by the participants in communication as much as the single message then to be selected from that constructed set, also known as the context (Baecker, 2013, p.1).

Many other researches have been conducted, shedding light on life in light of the pandemic and portraying its effects. Many researchers have concentrated on the effect of this pandemic on different fields of life such as arts, languages, philosophy, woman's literature, social sciences, health, field studies, communication sciences, family issues, alternative cultures, development, history, digitization, and epidemiology. For example, the reality of remote university education and educational technology have been discussed in light of the exceptional circumstances imposed by the epidemiological situation in Algeria as a result of the outbreak of the new Corona virus in March 2020 which necessitated the implementation of a set of measures within the application of the quarantine of the Algerian Ministry of Health. Another researcher presented the necessary strategies for living compatibility in light of the 
presence of the Corona virus inside the Palestinian society and its relationship to some variables. This was done through a field study on a sample of government school principals in the Hebron Governorate in southern Palestine. The research was conducted by school principals in the Palestinian society, and the sample consisted of 30 from the category of school principals mentioned in this community (Alawna\&Alsheweiki, 2020, p.202). Also, some researchers shed light on the level of social awareness of the Covid-19 among rural people in the village of Bandar Toukh in Qalyubia Governorate and the village of Ibshway in Fayoum Governorate, using social survey method and electronic questionnaires (Mohammed \& Mohamed, 2020, p.969).

In June 2020, Karen KY Leung and other researchers in a research paper entitled "Coronavirus disease 2019 (COVID-19): latest developments in potential treatments" have affirmed thatSARS-CoV-2 vaccine development is ongoing, and numerous clinical trials are currently taking place around the world. Existing antivirals such as remdesivir and lopinavir-ritonavir may have a role in the treatment of COVID-19although preliminary results have not been promising. In the majority of cases, COVID-19 causes a moderate respiratory infection, but in certain cases cytokine activation causes sepsis and acute respiratory distress syndrome, resulting in morbidity and fatality (Leung et al., 2020). In May 2021, Luciano Lopes in a research paper entitled "From SARS to COVID-19: lessons we should have learned (but we did not)" has briefly covered the lessons learnt by the countries which fought the SARS pandemic and which were successful in containing it. He also discussed some of the major factors that contributed to failures to handle the Coronavirus disease 2019 (COVID-19) pandemic. He added:

In the Brazilian context, the federal government has delayed the necessary measures to be taken, has been 
less transparent to disclose health data, has neglected the face mask usage mandates, and has refused the COVID-19 vaccine offerings. Therefore, despite the previous Coronavirus outbreaks, we are suffering during the COVID-19 pandemic because we did not learn about SARS (Lopes, 2021).

Hossain and others have emphasized the critical importance of knowing the temporal dynamics of public sentiment around Covid-19 vaccinations in the United States on a national and state-wise level in order to facilitate effective public policy applications. Despite the overall strength of positive sentiment and the increasing number of Americans who are fully vaccinated, their analysis of social media data from early February to late March 2021 shows that negative sentiment toward COVID-19 vaccines persists among segments of people who are hesitant towards the vaccine. In this study, they have performed sentiment analytics on vaccine tweets, monitored changes in public sentiment over time, contrasted vaccination sentiment scores with actual vaccination data from the US CDC and the Household Pulse Survey (HPS), explored the influence of maturity of Twitter user-accounts and generated geographic mapping of tweet sentiments (Hossain et al., 2021).

\section{Theoretical Framework}

\subsection{Shannon-Weaver's Model of Communication}

The Shannon and Weaver Model of Communication is a mathematical theory that claims that human communication can be broken down into 6 fundamental concepts: sender, encoder, channel, noise, decoder, and receiver. Norbert Weiner's subsequent version of the theory introduced a seventh element ('feedback') that transformed the model from linear to cyclical. Because of its widespread appeal, it is known as the "mother of all models."As both Claude and Shannon established the idea, it is 
sometimes known as "information theory" or "Shannon theory." The model's main benefit is that it explains how messages are lost and corrupted during the communication process. It's a communication model that uses a linear framework to examine how messages are conveyed and received. It is most renowned for its ability to explain how messages can be misinterpreted and misconstrued during the transmission and reception process. Shannon in his renowned work entitled "A Mathematical Theory of Communication" emphasized that the fundamental challenge of communication is replicating a message delivered from one place to another, either perfectly or approximately (Shannon, 1948, p. 379).He intended to more effectively pinpoint those pressure points where communication is affected by using this mathematical theory of communication. This theory of communication follows the concept of communication in a linear form from sender to receiver as seen below:

\subsubsection{Sender (Information Source)}

The sender is the transmitter which converts the message into signals (the way message is changed into signals, for example sound waves). The sender, also known as the communicator or source of communication, is the one who originates a message in the communication process. The sender could be a public speaker, a writer, or someone who communicates by gestures. The sender is the one who gives his or her statements and speeches credibility and validity, but attractiveness and friendliness also play a role in receiving the message. The sender's function in communication defines both the tone and the expectation of the dialogue, from the ethos of the sender's speech to the character he or she portrays. In writing, however, the answer takes longer and is based more on the sender's reputation than on his or her image (Nordquist, 2019).The Shannon Weaver model starts with the sender or "information source". The sender can send a message in multiple 
ways: it may be orally (through spoken language), in writing, through body language, music, etc.

\subsubsection{Encoder (Transmitter)}

The encoder is the equipment (or person) that turns the sender's message or ideas into signals to be sent and communicated to the receiver. The Shannon model was created to describe how we communicate using devices like the telephone and computers which encode our words using binary digits or radio waves. The encoder, on the other hand, can be a person who converts an idea into spoken words, written words, or sign language in order to express it to another person. The encoder may be a phone that turns our voice into binary $1 \mathrm{~s}$ and 0 s before sending it down the phone lines (the channel). Another encoder may be a radio station that turns voice into waves and sends them to someone via radio (Drew, 2019). The process of converting thoughts into communication is known as encoding. The encoder sends the message via a 'medium,' such as a phone call, email, text message, face-to-face meeting, or other means of communication. The amount of deliberate consideration that goes into encoding messages varies. Any 'noise' that might interfere with their message such as other messages, distractions, or influences should be considered by the encoder.

\subsubsection{Channel}

Drew (2019) refers to the infrastructure that transports data from the sender and transmitter to the decoder and receiver as "the communication channel." This is also known as the 'medium.' The World Wide Web (internet) is used as a medium by someone sending an email. When chatting on a landline phone, the channel is made up of cables and electrical wires. If we're talking face to face, we may not have a channel other than the sound waves from our voices, which convey sound from the sender's lips to the receiver's ear. Communication channels are mediums through 
which a message can be delivered to its target audience. Phone conversations, text messages, emails, video, radio, and social media, for example, are all forms of communication channels.

\subsubsection{Noise}

'Noise' is another step in this model of communication. Noise interrupts the transmission of a message from the sender to the receiver. It's named from the premise that it may hinder one's understanding to a message. Internal and external noise is the two types of noise. When a transmitter makes a mistake encoding a message or when a receiver makes a mistake decoding a message, internal noise occurs. An example is either misspelling a word from the side of the sender or misinterpreting a sentence when reading an email. External noise occurs when something outside the transmitter or receiver's control obstructs the message. One of the main objectives for those who utilize this theory is to identify the sources of noise and try to reduce them in order to improve the message's quality (Drew, 2019).

\subsubsection{Decoder}

The reverse of encoding is decoding. As this model has been created by Shannon and Weaver in reference to communication that occurs through devices such as telephones, in this approach a device that decodes a message from binary digits or waves into a format that the recipient can understand is frequently required. There may still be a need for decoding if we're talking about direct communication between humans without the aid of technology. For example, you might need to decode a secret message, read written words aloud to make them make sense in your mind, or understand (decode) the meaning behind and picture sent to you. Computers that convert binary packets of $1 \mathrm{~s}$ and 0 s into pixels on a screen that form words, telephones that convert signals like digits or waves back into sounds, and cell phones that convert bits of data into readable (and listenable) 
messages are all examples of decoders. The Traditional EncodeDecode Model of Human Communication is obvious in figure (2).

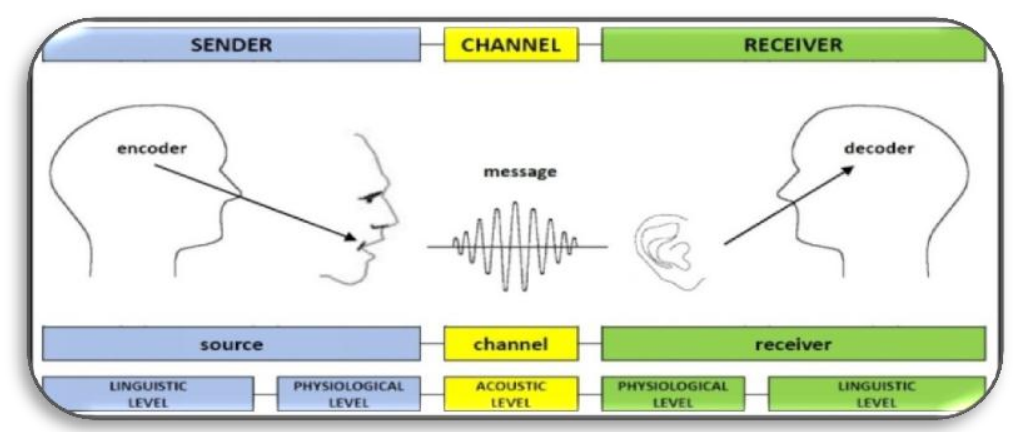

Figure (2): The Traditional Encode-Decode Model of Human Communication (Williamson, 2014)

\subsubsection{Receiver (Destination)}

In communicating together there must be somebody at the other end of the channel. This person or persons can be called the receiver (To whom the message is presented). Information transmitters and receivers must be similar systems. If they are not, communication will be impossible. Shannon used the term destination, reserving the term receiver for what we have called decoder. The receiver needs to have the equipment to receive the message. A totally blind person has the mental equipment to decode gestures, but no system for receiving messages in the visual channel. The person on the other end of the phone, the person reading an email you sent them, an automatic payments system online that has received credit card details for payment, and so on are all examples of receivers.

\subsubsection{Feedback}

Shannon and Weaver did not suggest the 'feedback' phase when they published their book in 1948. In response to criticism of the linear character of the approach, Norbert Weiner devised the feedback stage. (The term 'linear' refers to the fact that the 
messages are only sent in one direction.) When the receiver of a message reacts to the sender in order to complete the communication loop, this is known as feedback. They may answer to inform the sender that they received the message or to demonstrate to the sender whether they got the message clearly without noise and how well they understand the message. Feedback does not occur in all situations. When we're watching $\mathrm{TV}$, for example, we don't always express our thoughts to the individuals on the screen; instead, we simply watch the show. Feedback occurs during a chat between friends, in writing a reply email, or through facial expressions and body language during a conversation (Drew, 2019).

\section{Sample Analysis}

\subsection{WHO Director-General's remarks at the 1st International} Forum on Vaccine Cooperation

\subsubsection{Introduction}

World Health Organization began to set certain rules to make all people be aware of the danger of the pandemic after its spread. It put guidelines related to the pandemic, the treatment protocol for patients suspected of being infected, the ventilator protocol for patients, the diagnostic and therapeutic protocol for thrombosis and thrombocytopenia caused by vaccines, a guide to dealing with deaths of people infected with the new Corona virus, guidance in basic and cardiac life support (BLS and ACLS) for adults, children, and newborns with Covid-19, dental emergency guide in dealing with the pandemic, preparedness plan for the radiology departments in fighting the pandemic, National Organ Transplant Center guidelines for organ transplantation and donation for people infected with Coronavirus, Clinical Nutrition Guideline during the pandemic, and physiotherapy recommendations for patients in critical cases. In this research, the researcher tries to reveal the role of WHO in fighting the pandemic through applying 
one of the models of communication to certain speeches given by officials concerning the pandemic. For example, ShannonWeaver model of communication has been employed in the analysis of the speech given by WHO director-general at the 1st International Forum on Vaccine Cooperation.

\subsubsection{Analysis}

Sender: The person starting the conversation is the sender. This speech has been given by the director general of the World Health Organization, Dr.Tedros Adhanom Ghebreyesus. In May 2017, WHO Member States elected him as Director-General for a fiveyear term at the Seventieth World Health Assembly. He is the first WHO Director-General to be elected by the World Health Assembly, and the first person from the WHO African Region to serve as the organization's main technical and administrative official. Dr. Tedros outlined some core targets for the WHO shortly after taking office in July 2017: universal health coverage; health emergencies; women's, children's and adolescents' health; and health impacts of climate and environmental change.

Encoder: The 'encoder' step is usually used to explain a machine that encodes a message for transmission. In this face to face speech, the 'encoding' can be considered the ways the sender turns his idea into intelligible words and sentences. As this speech can easily be listened via television, the television turns the person's voice into a series of binary data packages to be sent down the electronic lines. In case of listening to it via radio, the microphone and its computer will turn the voice of the radio host into binary packets of data that are sent to the radio transmitter. The radio transmitter, as part of the encoder, will turn that data into radio waves ready to be transmitted.

Channel: There isn't any wire or radio waves involved through face to face communication. Instead, the sound is transmitted through sound waves made by the voice. In case of listening to it 
via television or radio, the channel will be the waves of the radio or the television that are sent out by the transmitter.

Noise: In case of face to face communication, the speaker's accent might cause the message to be distorted (internal noise). There might be a wind or traffic that made the message hard to hear (external noise).In case of listening to it via television or radio, noise is most likely to occur if the receiver's transistor radio or television is not tuned to the correct frequency, causing static, or if the receiver's transistor radio or television is too far away from the transmitter.

Decoder: Through face to face communication or through listening to the speech of the director directly, the listener still has to turn the words he/she hears into a legible message in his/her mind since there is no machine. However, in case of listening to it via any electronic device such as radio or television, the decoder is the receiver's transistor which will turn the waves back into voice.

Receiver: The receiver is all those who listened to this speech. This speech generally is directed to all those who have a desire to listen to the instructions given by WHO for avoiding the danger of the pandemic. In case of listening to it via any electronic device such as radio or television, the receiver is the person listening to the radio or television that will hopefully receiver the full message loud and clear if noise has been avoided or minimized. So, the receiver of this speech is not a specific person; it is a general speech directed for the sake of all people around the world.

Message: This speech has been presented for different purposes. The director general of WHO through this speech shed light on the worldwide vaccine that the whole world hopes to discover for solving the worldwide crisis. For him, the creation and widespread use of multiple safe and efficient vaccines to combat Covid-19 is a remarkable scientific achievement, and that hope is 
essential for putting the epidemic under control. He referred to the problem of the imbalance in the global distribution of vaccines. He stressed the danger that might face the countries which did not get that vaccine, linking the spread of the virus to not getting the vaccine and referred to the keen of all governments to let all people get that vaccine. All governments did their best to save more than 11 billion doses of vaccine. He said:

Over 4 billion vaccines have been administered globally, but more than $75 \%$ of those have gone to just ten countries, often secured through bilateral deals that have bypassed COVAX. Vaccine inequity is not only a moral failure, it is also epidemiologically and economically self-defeating (WHO Director-General).

He sent special thanking to the Chinese government out of its generous contribution with about US\$100 million to COVAX to save lives around the world. In addition, he thanked WHO that was eager to support low- and middle-income countries to strengthen their capacity to roll out vaccines effectively and efficiently, promising to scale up the number of vaccines being produced for lower-income countries through technology, profits, action, cooperation, innovation, solidarity and manufacturing.

Feedback: In giving this speech without receiving any reaction from attendees, feedback becomes not obvious out of the inability of the speaker to realize the reaction of all attendees towards his main message. The receiver may speak in response to let the sender know what they heard or understood, but in this speech no one responded to the speaker, giving him no feedback. Through electronic communication or listening to this speech via T.V. or radio, feedback becomes difficult. However, the radio channel may send out speakers into the field to interview listeners to see how effective their communication has been. Face-to-face 
communication involves lots of feedback as each person takes turns to talk, but in this speech no one responded to the speaker.

\subsection{Launch of WHO Handbook on Social Participation for Universal Health Coverage}

\subsubsection{Analysis}

Sender: The sender of this speech is Michelle Bachelet, the United Nations High Commissioner for Human Rights since September, 2018. She is the seventh Commissioner. She was the first female president of Chile. Ms. Bachelet was elected twice as President of Chile (from 2006 to 2010 and from2014 to2018). She served as Health Minister from 2000 to 2002 as well as Chile's and Latin Am

erica's first female Defense Minister from 2002 to 2004.During her presidential period, she promoted the rights of all but particularly those of the most vulnerable. Education and tax reforms, the establishment of the National Institute for Human Rights and the Museum of Memory and Human Rights, the Ministry of Women and Gender Equality, the adoption of quotas to increase women's political participation, and the approval of Civil Uniforms are among her many accomplishments. In this speech she tried to send a valuable message to the whole world for shedding light on health after the spread of Covid-19.

Encoder: Like the previous speech, as this speech can easily be listened via television, the television turns her voice into a series of binary data packages to be sent down the electronic lines. In case of listening to it via radio, the microphone and its computer will turn the voice of the radio host into binary packets of data that are sent to the radio transmitter. The radio transmitter, as part of the encoder, will turn that data into radio waves ready to be transmitted. In case of face to face communication, the 'encoding' can be referred to the ways Michelle Bachelet turned her ideas into intelligible words and sentences. 
Channel: Face-to-face or personal communication is one of the richest channels of communication that can be used within an organization. Physical presence of the speaker, the tone of her voice and facial expressions helped recipients of the message interpret that message as she intended. This is the best channel to use for complex or emotionally charged messages as it allows for interaction between speaker and recipients to clarify ambiguity. In communicating face-to-face, she could evaluate whether the audience received her messages or not. There isn't any wire or radio waves involved through face to face communication. Instead, the sound is transmitted through sound waves made by the voice. In case of listening to it via television or radio, the channel will be the waves of the radio or the television that are sent out by the transmitter.

Noise: Noise is anything that distorts the message, whether physical (like a jackhammer), jargon (like slang), inappropriate body language (like not facing you), facial expression (like a frown), inattention (like texting while one is talking), disinterest (like yawning), and cultural differences (like accents or eye contact). In case of face to face communication, she may have mumbled or had an accent that caused the message to be distorted (internal noise). There might be a wind or traffic that made the message hard to hear (external noise).In case of listening to it via television or radio, noise is most likely to occur if the receiver's transistor radio or television is not tuned to the correct frequency, causing static, or if the receiver's transistor radio or television is too far away from the transmitter.

Decoder: Through face to face communication or through listening to her speech directly, it was the listener's role to turn the words he/she hears into a legible message in his/her mind since there is no machine. However, in case of listening to it via any 
electronic device such as radio or television, the decoder is the receiver's transistor which will turn the waves back into voice.

Receiver: The receiver is all those who listened to this speech. This speech generally is directed to all those who have a desire to listen to the instructions given by WHO and all officials for avoiding the danger of the pandemic. In case of listening to it via any electronic device such as radio or television, the receiver is the person listening to the radio or television that will hopefully receiver the full message loud and clear if noise has been avoided or minimized. So, the receiver of this speech is not a specific person; it is a general speech directed for the sake of all people around the world.

The receiver could decode the news based on his/her understanding. They have succeeded in communicating only when the message translated is the same as the original idea.

Message: This speech was given for universal health coverage. The speaker sent a valuable message through this speech. She stressed the value of social protection for all societies, considering this part of human rights. She added that all workers inside the ministry of health sacrificed their life for the rest of all people, asserting that human rights and public health go hand in hand. After the spread of Covid-19, she stressed the necessity for implementing public health measures and advised all peoples to participate in taking right decisions for fighting the pandemic, rebuilding health systems, economies, businesses and societies, and for the success of health policies. She also noted that both universal health coverage and the underlying determinants of health should have been included within health and social protection systems; this could be achieved when saving medical care to all those who required medical attention and services. All systems that protect human rights in times of crisis must receive special interest. 
Feedback: Face-to-face communication helps to build collaborative environments that inspire innovation and good understanding. One of the benefits of face-to-face communication is the instant feedback translated through body language and facial expressions. We can also hear the tone of voice, which makes it easier to interpret the person's feelings. In case of listening to this speech directly through live communication, the speaker has a good opportunity to receive the reaction of the listener. Like the previous speech, the receiver may respond to let the speaker realize what they understood, but in this speech no one responded to the speaker, giving her no feedback. Through electronic communication or listening to this speech via T.V. or radio, feedback becomes difficult. However, the radio channel may send out speakers into the field to interview listeners to see the effectiveness of their communication.

\subsection{Social Sciences in response to Covid-19}

\subsubsection{Introduction}

During the period of Covid-19 and after about one year from its dominance many articles have been written on it. In this research Shannon-Weaver model of communication will also be applied to two articles written on the shape of life in light of the pandemic. Hence, although the employed theory is better to be applied to spoken language, the researcher will analyze one article using this theory to reveal certain pivotal issues on the pandemic such as social sciences and field studies. In the wake of the outbreak of the Corona Virus (Covid-19) pandemic, we have followed different governments that rely heavily on scientific research in making their decisions. However, much work is still needed to bridge the influential social science gap, especially as the world's policy makers will face the challenges and prospects of recovery from the virus even after the pandemic, and that every political choice made will contribute to shaping the features of our 
post-pandemic world. The pandemic and applied research in the field of social sciences can provide clues and insights that can be used in decision-making processes.

\subsubsection{Analysis}

Sender: The sender of this article is Rachel Middlemass. She works at the London School of Economics as a Research Impact Manager. Her responsibilities include advising academic departments and individual researchers on the development of impact strategies, providing knowledge exchange and impact training to $\mathrm{PhD}$ students, contributing to internal knowledge exchange funding and activity decisions, and helping in the development of REF impact case studies. She is also in charge of the LSE's response to the Knowledge Exchange Framework (KEF) and Knowledge Exchange Concordat which will be released soon. Rachel has worked on knowledge exchange and impact in a variety of higher education institutions since completing her $\mathrm{PhD}$ in mediaeval history. In this article, she converted her main ideas into words to convey meaning. She tried to change information into some form of logical and coded message. She selected appropriate language, medium of communication, and communication form. Selecting the right language is pivotal for effective encoding. Verbal messages need a common language code which can be easily decoded by the receiver. In choosing proper words and signs, the writer must be alert to the receiver's communication skills, attitudes, background, experiences, and culture.

Encoder: Writing involves the selection of the correct written form such as letter, memo, notice, report, proposal, etc. In written language, the sender seems to be the encoder. Her ideas can easily be conveyed to the decoder through the chosen words and sentences. 
Channel: The basic channel in this article is written (hard copy print or digital formats). Channel richness refers to the amount and immediacy of information that can be transmitted. This article includes supporting data and detailed explanations for persuading the receiver about a course of action. Written communication can be carefully crafted to say exactly what the sender means. Faceto-face communication is very high in richness because it allows information to be transmitted with immediate feedback. However, in written articles message can be revised for exactness; can be archived for reference; and it can be studied. A written note will be useful documentation for future reference. Figure (3) shows the richness of different types of communication.

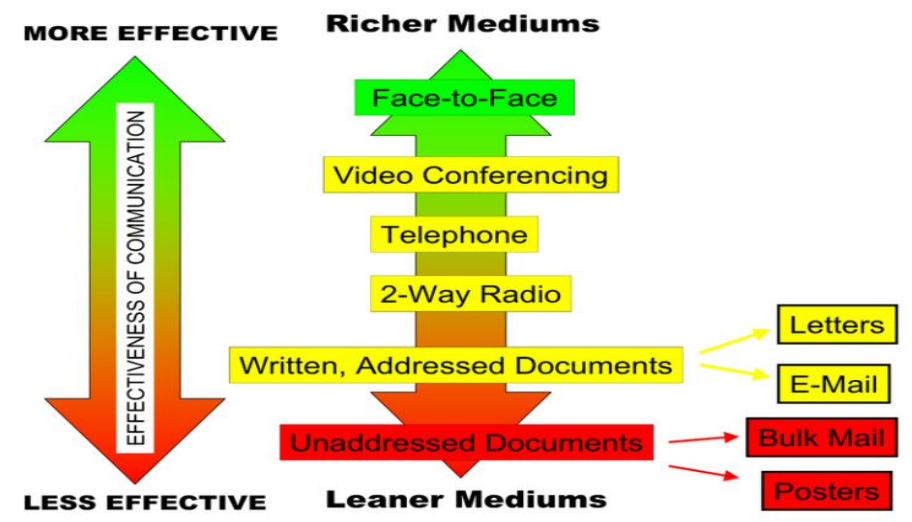

Figure (3): The richness of different types of communication

("Channels of Business Communication,"n.d.para.2)

Noise: In this article noise is latent in any element that interferes with the generation of the intended meaning in the mind of the receiver. Noise may arise in the source, in the channel; or in the receiver. Not using suitable language in writing is a kind of noise. So, there is a kind of noise for some in the opposite of others. "Misusing a word or phrase can adversely affect the receiver's understanding of the message. This type of distraction referred to as semantic noise. It also encompasses jargon, slang and even specialized professional terminology (as 
cited in Nordquist, 2020)."The sender may also inadequately encode the original message with words not present in the receiver's vocabulary. That is to say, ambiguity in writing is a kind of noise.

Decoder/ Receiver: This article is directed to all those who are concerned with studying life during and after Covid-19. So, it may be directed to researchers in particular and public reader in general who have the ability to judge the topic. The receiver who is close-minded and unreceptive to new and different ideas faces a problem in realizing the main message behind the article.

Message: Through this article, certain messages have been sent from the writer to the reader. According to the writer, for example, science in general and social sciences in particular play a decisive role in fighting Covid-19. Social scientists themselves have a powerful role in helping people overcome the pandemic; the analysis and insights social sciences generate can help guide and target insights from the 'natural' sciences. For example, the effective and acceptable delivery of mass vaccination programs is one of the targets of social scientists themselves. Social sciences also have a decisive role in reflecting the voices of communities affected by this worldwide issue, and relevant stakeholders are able to be involved in decisions that affect them. Involving businesses and communities in developing a strategy for inclusive and sustainable recovery is one of the interests of social sciences. A post-recovery world will benefit from the decisive contributions that social sciences make in areas like increasing the resilience of our democracies and financial systems, exposing and correcting social and economic inequities, and promoting good mental health and more sustainable ways of living. Social sciences' anthropological work is critical in providing a good advice during any crisis in order to preserve lives and limit the 
spread of the outbreak. As a result, local information which the social sciences may supply is crucial.

Another important message delivered by the writer is that Covid-19 has devastated communities and economies around the world, changing the ways in which people live and work. After the spread of the pandemic, researchers around the world have employed field studies for portraying the shape of life in light of Covid-19. Social scientists can help policy-makers develop solutions that people are able to follow. One of the decisive ways in fighting the pandemic is cooperation with industry, communities and third sector organizations, as well as with policy-makers. Collaboration between and within academic disciplines is also important. Collaboration with STEM colleagues and encouraging scientific research is another step towards progress; it is the role of many universities to promote and support interdisciplinary research. Social Sciences, Humanities and Arts, Field Studies, and improving economy should be the decisive ways to level up the standard of all communities who are infected with this fatal virus. Evaluating and communicating the benefits of social science research is essential. So, governments begin to incentivize and reward researchers and academics to participate in the development of the scientific research and the exchange of knowledge through supporting their efforts and celebrating their success.

Feedback: Feedback is an essential component of communication process. Without feedback, none can ensure the effectiveness of communication. In the opposite of oral communication, in written communication feedback becomes not obvious. The writer has no ability to get at the reaction of his readers. This step may become later through receiving certain notes from the reader who has the ability to write comments on the information given by the writer. Feedback in communication is shown in figure (4). 


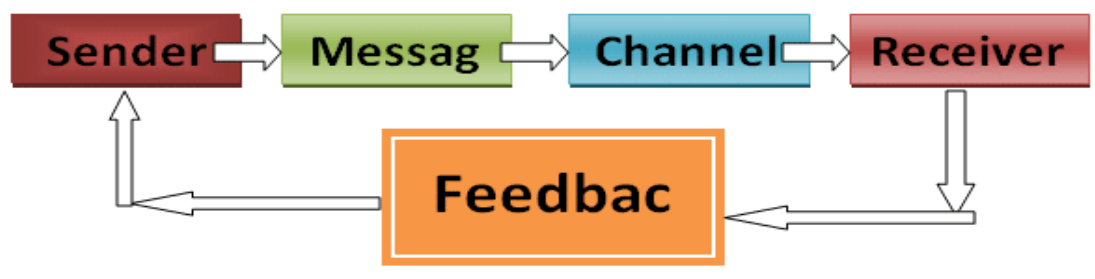

Fig: Feedback in communication

Figure (4) Feedback in communication ("The Business

Communication,"2021)

\section{Conclusion}

Through this study the researcher comes to the conclusion that models of communication can help in analyzing any piece of writing, whether written or spoken. This paper supplements current understanding of certain fundamental concepts employed in the chosen model. The results seem very promising as a step toward developing a unified approach to the study of communication. The usefulness of the chosen model is that it highlights the different elements of communication and it points to interrelationship among the elements. Moreover, it describes the role each element plays in the process and explains the commutation flow. The chosen model has been developed from extremely simple one to very complex one by eminent scholars. From another direction, the researcher has tried properly to portray social life during and after the spread of the pandemic. She asserts that during the pandemic the wheel of life has been disrupted during a decade characterized by the acceleration of work towards achieving sustainable development and disrupted by a global health threat that has seriously damaged the Arab region. The focus shifted to emergency action to save lives and repair livelihoods. The crisis is a resounding cry, telling the whole 
world that the public sector is the first line of defense in dealing with systemic risks.

\section{Recommendations and Suggestions}

Many other theories of communication can be employed in the analysis of the chosen samples such as Lasswell's Model, Berlo's S-M-C-R Model, Osgood-Schramm Model, The Westley and Maclean Model, Barnlund's Transactional Model, or Dance's Helical Model. The chosen model in this research can also be applied to many other samples for revealing many other dimensions of life in light of the pandemic such as political life, economic life, or educational life. Other theories outside the field of communication can be suggested for analyzing the chosen samples or many other speeches or articles such as Dell Hyme's speaking theory or Faircloughian approach within the field of discourse analysis. In addition, many semiotic theories such as that of Charles Peirce or Roman Jakobson can be employed in other researches in revealing the same issue by being applied to images, caricatures, speeches, or articles. 


\section{References}

Alawna, Abdulmegid\&Alsheweiki, Hanaa. (2020). The Necessity Strategies for the Compatibility of Living in light of Corona Virus within the Palestinian Society and its Relationship to some Variables: A Field Study on a Sample of Directors of Governmental Schools in Alkhalil Governorate in 2020. Arab Journal for Scientific Publishing (AJSP) 23, 181-202. www.ajsp.net

Al-Fedaghi, Sabah.( January, 2012). A Conceptual Foundation for the Shannon-Weaver Model of Communication.International Journal of Soft Computing7 (1), 12-19.DOI:

10.3923/ijscomp.2012.12.19. Retrieved from, https://www.researchgate.net/publication/272964534

Baecker, Dirk. (2013). Systemic Theories of Communication.1-26.

DOI: 10.1515/9783110240450.85. Retrieved August 26, 2021, from

https://www.researchgate.net/publication/306143640

Baguley, P. (1994). Effective Communication for Modern

Business. U.K.: McGraw Hill Book.

Ben Break, Anas. (February 14 2021). The Future of Social Sciences

Researches in Post Covid-19 World (F. Tawakol, Trans.).

Retrieved August 17, 2021, from

https://www.hbku.edu.qa/ar/news/post-Covid-world

Bhasin, Hitesh. (February7, 2021).Communication Process -

Definition, Importance, Components and How to Improve.

Retrieved August 19, 2021, from

https://www.marketing91.com/communication-process/

Bovee, C.L., \&Thill, J.V. (1992).Business Communication

Today.

NY, NY: McGraw-Hill

Burnett, M.J., \& Dollar, A. (1989). Business

Communication: Strategies for Success. Houston,

Texas: Dane.

(Social Life after Covid-19...)Dr. Fatma Tawakl Gaber 
The Business Communication.(2021). Retrieved September 9,2021, from

https://thebusinesscommunication.com/what-iscommunication-feedback-causes-of-poor-feedback/

Channels of Business Communication.(n.d.). Retrieved September 6, 2021, from https://courses.lumenlearning.com/wmprinciplesofmanagement/chapter/channels-of-businesscommunication/\#: :text=A\%20communication\%20channe $1 \% 20$ is $\% 20$ the,spoken $\% 2 \mathrm{C} \% 20$ and $\% 20$ electronic\%20and $\% 20$ multimedia.

Drew, Chris. (September29, 2019). Shannon Weaver Model Of Communication - 7 Key Concepts. Retrieved August23, 2021, from

https://helpfulprofessor.com/shannon-weaver-model/ Fawzy, Sameh. (June 6, 2020). Social Sciences Silence towards Covid-19.(F. Tawakol, Trans.). Retrieved August 15, 2021, from

https://gate.ahram.org.eg/daily/NewsPrint/765492.aspx Hossain, M.A,et.Al.(2021). Public Perceptions of COVID-19 Vaccines: Policy Implications from US Spatiotemporal Sentiment Analytics. Healthcare 2021, 9, 1110. https://doi.org/10.3390/healthcare9091110

Leung,Karen,et al. (June,2020). Coronavirus disease 2019 (COVID19): latest developments in potential treatments. Drugs in Context 2020; 9: 2020-4-15. DOI: 10.7573/dic.2020-4-15 Lopes, Luciano. (May, 2021). From SARS to COVID-19: lessons we should have learned (but we did not). Journal of Evidence-Based Healthcare. DOI: 10.17267/2675021Xevidence.2021.e3837. Retrieved August26, 2021, from https://www.researchgate.net/publication/354170587 
Lucas, Amy. (2015, April 15). The Importance of Verbal \& Non Verbal Communication. Retrieved August 12, 2021, from http://www.livestrong.com/article/156961-the-importanceof-verbal-non-verbal-communication/

Mayo Clinic Staff. (2021). COVID-19 (coronavirus): Long-term effects. Retrieved August 15, 2021, from https://www.mayoclinic.org/diseasesconditions/coronavirus/in-depth/coronavirus-long-termeffects/art-20490351

Middlemass, Rachel. (August25, 2020). What is the role of the social sciences in the response to COVID-19? 4 priorities for shaping the post-pandemic world. Retrieved September3, 2021, from

https://blogs.1se.ac.uk/impactofsocialsciences/2020/08/25/whatis-the-role-of-the-social-sciences-in-the-response-to-Covid19-4-priorities-for-shaping-the-post-pandemic-world/ Models of Writer Communication: The Elements of Good Communication Models. (n.d.). Retrieved August 11, 2021, from

jusur.edu.sa/portal/modules/courses_list/PDF/.../Topic_3.pdf

Mohammed, Rabab\& Mohamed, Heba. (November 14, 2020). Social Awareness of Rural People with the Covid-19 ( A Field Study in the Villages of Bandar Toukh in Qalyubia Governorate and Abshway Village in Fayoum Governorate). Arab Univ. J. Agric. Sci 28 (4), 949-969Website: http://ajs.journals.ekb.eg

Murpdy, Herta\& Hildebrandt, Herbert. (1991). Effective Business

Communication. (6 ${ }^{\text {th }}$ ed.). New York: McGraw-Hill.

Nordquist, Richard. (2019). Definition and Examples of Senders in

Communication. Retrieved August 15, 2021, from https://www.thoughtco.com/sender-communication-1691943 
Nordquist, Richard. (August26, 2020).Noise and Interference in

Various Types of Communication.Retrieved September 6, 2021, from

https://www.thoughtco.com/noise-communication-term1691349

Shannon, C. (1948). A Mathematical Theory of

Communication. The Bell System Technical Journal, 27(1): 379-423.

WHO Director-General. (August 5, 2021). WHO Director-General's remarks at the 1st International Forum on Vaccine Cooperation. Retrieved September 2, 2021, fromhttps://www.who.int/directorgeneral/speeches/detail/who-director-general-s-remarks-atthe-1st-international-forum-on-vaccine-cooperation---5august-2021

Williamson, Graham. (January 29, 2014). The Encode-Decode Model of Communication. Retrieved August 18, 2021, from https://www.sltinfo.com/the-encode-decode-model-ofcommunication/

World Health Organization.(2021). Healthy at Home. Retrieved August 16, 2021, from https://www.who.int/campaigns/connecting-the-world-tocombatcoronavirus/healthyathome?gclid=CjwKCAjwjdOIBhA_Eiw AHz8xm7aGK0Z_QMwk8qcBQ9 gqqFMt5ZL104oqvuP2ei XLvvGaXPf-NAPWhoC-OgQAvD BwE 


\section{ملخص}

يأمل العديد حول العالم إلى اليوم الذي تعود فيه حياتهم للافضل بعد مرور قرابه عام

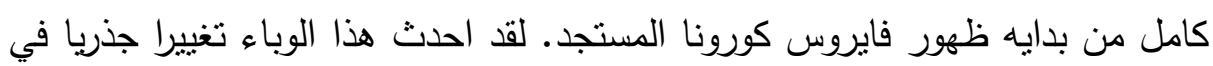
طريقة حياه الناس وتفاعلهم الاجتماعي حيث كان لله تاثيرا عالميا فالحياه قد تغيرت

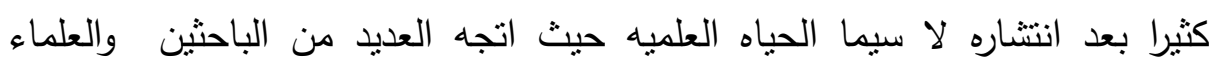

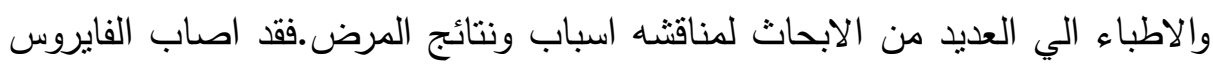

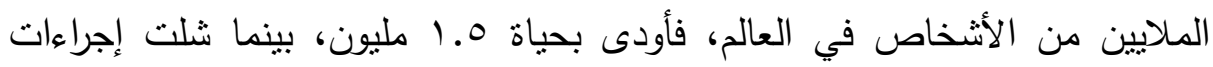

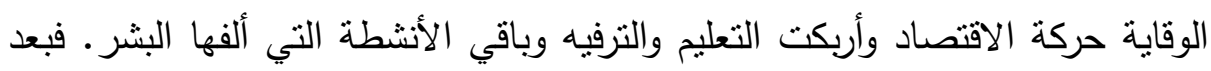

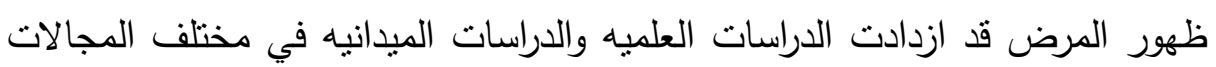
لالقاء الضوء علي الحياه بعد الجائحه وكيف اثر هذا الفايروس علي مجالات الحياه

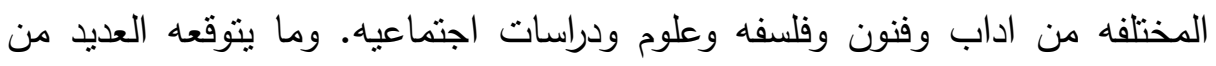

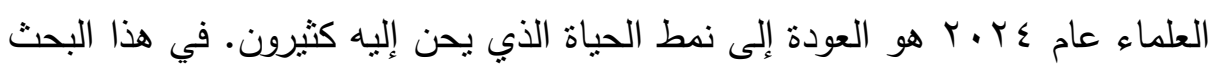

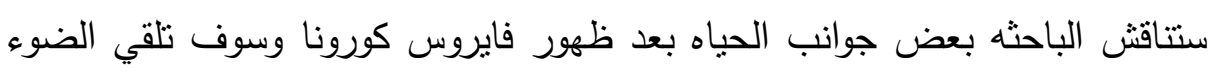

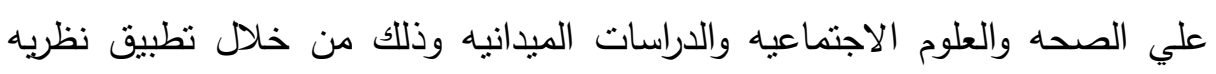

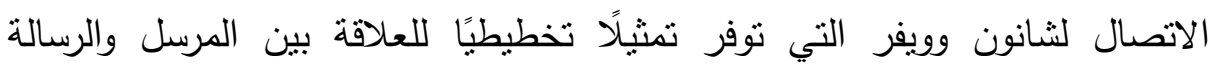
والوسيط والمتلقي علي خطابين قد القاهمااثنان من الثخصيات البارزه وعلي مقاله كتبتها باحثه مرموقه من اجل تصوير الحياه بعد الجائحه. فالنظريه المختاره نوفر إطارًا

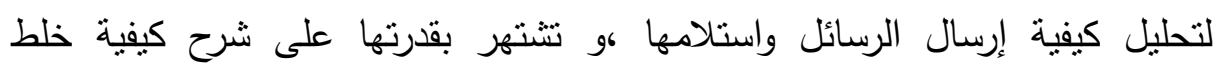
الرسائل وإساءة تفسيرها في العملية بين إرسال الرسالة واستلامها.وبذلك ستكون النظريه

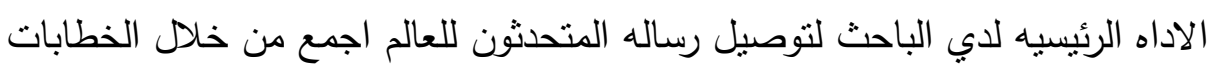
المختاره والمقاله المكتوبه.

الكلمات الافتتاحيه: فايروس كورونا المستجد، الصحه، العلوم الاجتماعيه ، الدراسات الميدانيه، نموذج الاتصال لشانون وويفر 